\title{
Use of femoral vein homograft for unifocalizing major aortopulmonary collateral arteries in a patient with pulmonary atresia with ventricular septal defect
}

\author{
Dingchao He, MD, Pranava Sinha, MD, Murfad Peer, MD, and Richard A. Jonas, MD
}

As a result of wide morphologic variation in ventricular septal defect (VSD) with pulmonary atresia and major aortopulmonary collaterals the 1-stage midline approach ${ }^{1}$ may not be appropriate for all patients. The alternative

From the Department of Cardiac Surgery, Children's National Medical Center, Washington, DC

Diclosures: Authors have nothing to disclose with regard to commercial support.

Received for publication March 21, 2013; revisions received July 8, 2013; accepted for publication July 26, 2013; available ahead of print Sept 26, 2013.

Address for reprints: Richard A. Jonas, MD, Department of Cardiac Surgery, Children's National Medical Center, 111 Michigan Ave NW, Washington, DC 20010 (E-mail: rjonas@cnmc.org).

J Thorac Cardiovasc Surg 2014;147:824-5 $0022-5223 / \$ 36.00$

Copyright (c) 2014 by The American Association for Thoracic Surgery http://dx.doi.org/10.1016/j.jtcvs.2013.07.078 staged unifocalization method popularized by Imai and colleagues $^{2}$ provides the advantage of excluding major aortopulmonary collateral segments with severe proximal stenosis by allowing access to the hilar segments of these vessels. We describe the use of cryopreserved femoral vein homografts $(\mathrm{cFVH})$ for unifocalization with its potential advantages.

\section{CLINICAL SUMMARY}

A 22-month-old boy with VSD with pulmonary atresia and absent true pulmonary arteries (see Figure 1, A) had 2 collaterals from the descending aorta supplying the left lung, and a single collateral to the right. All proximal
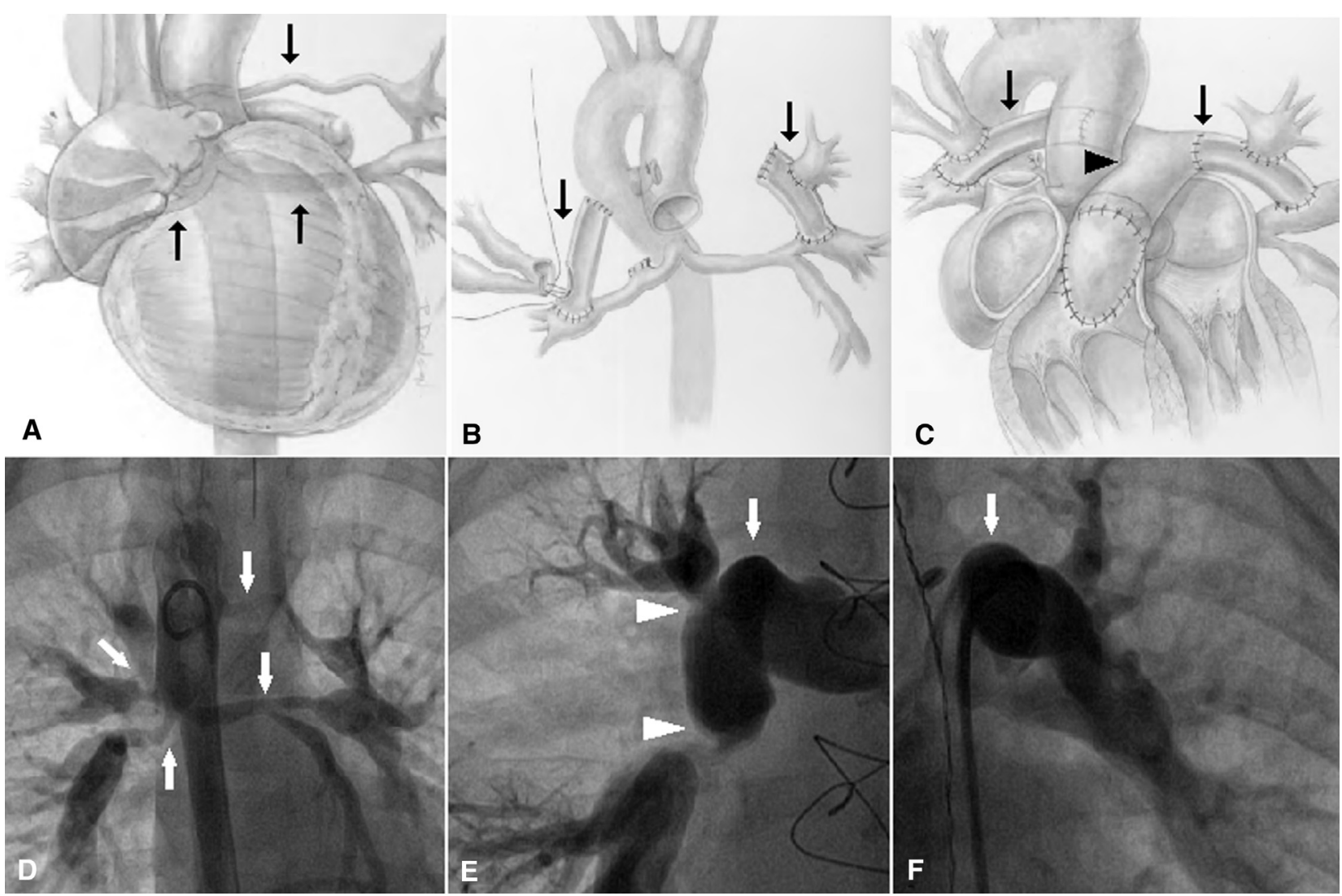

FIGURE 1. Depiction of preoperative and postoperative anatomy. A, Preoperative anatomy of major aortopulmonary collaterals showing long segment hypoplastic and stenotic collaterals (arrows). B, Unifocalization by end to side anastomosis of cryopreserved femoral vein homografts (arrows) to distal collaterals beyond stenotic segments. C, Completed repair with cryopreserved femoral vein homografts (arrows) anastomosed to bifurcated pulmonary homograft (arrowhead). D, Preoperative angiogram of major aortopulmonary collaterals showing long segment hypoplastic and stenotic proximal collaterals (arrows). E, Angiogram of unifocalized right pulmonary artery (arrow) post-stage 3, with stenosis of distal lobar vessels (arrowheads). F, Angiogram of left pulmonary artery (arrow) post-stage 3. 
collaterals had long-segment stenoses, and had complex anatomical relationships to the trachea and esophagus.

A 9-mm cFVH valveless segment was anastomosed to thin-walled segments of the left collaterals in the lung hilum via a left thoracotomy (Figure 1, B). The proximal upper left collateral was ligated and distal collateral left in continuity with the descending aorta as the systemic blood flow source to the unifocalized complex. After 1 week, via right thoracotomy, a 10-mm cFVH segment was anastomosed end to side to the right collateral, which was again left in continuity with the descending aorta (Figure 1,B). Lung perfusion scans after bilateral unifocalization revealed even blood flow distribution (55\% left and 45\% right) (Figure 2).

Finally via a midline sternotomy, the VSD was closed, the left and right cFVH segments were retrieved, and right ventricle to pulmonary artery continuity was restored using a bifurcated pulmonary homograft. One month later, $80 \%$ systemic right ventricle pressure was noted. Stenoses in the distal right pulmonary tree were addressed successfully by balloon angioplasty (Figure 1, $C, E$, and $F$ ). The aortic ends of the collaterals were coil occluded.

\section{DISCUSSION}

One-stage repair of pulmonary atresia, VSD, and major aortopulmonary collaterals with a high rate of collateral loss due to stenosis and thrombosis in the long term ${ }^{3}$ confines access to mediastinal and proximal hilar segments of the collaterals that are thick walled, muscularized, and stenosed. Although staged unifocalization avoids these diseased segments, earlier reports using autologous pericardial tubes, homografts, or xenografts $^{2}$ were limited by stenosis, thrombosis, and calcification, possibly due to the limitations of the conduits used.

cFVH has been used for neoaortic reconstruction in Norwood stage 1 operation and as a right ventricle to pulmonary artery valved conduit for biventricular repairs ${ }^{4,5}$ with encouraging outcomes. Lack of calcification and progressive somatic growth-matched dilation has been noted in these conduits. ${ }^{6}$ The thin-walled femoral vein also offers technical ease in anastomosing to similar thin and delicate pulmonary artery collaterals in the distal hilum and the lung fissure.

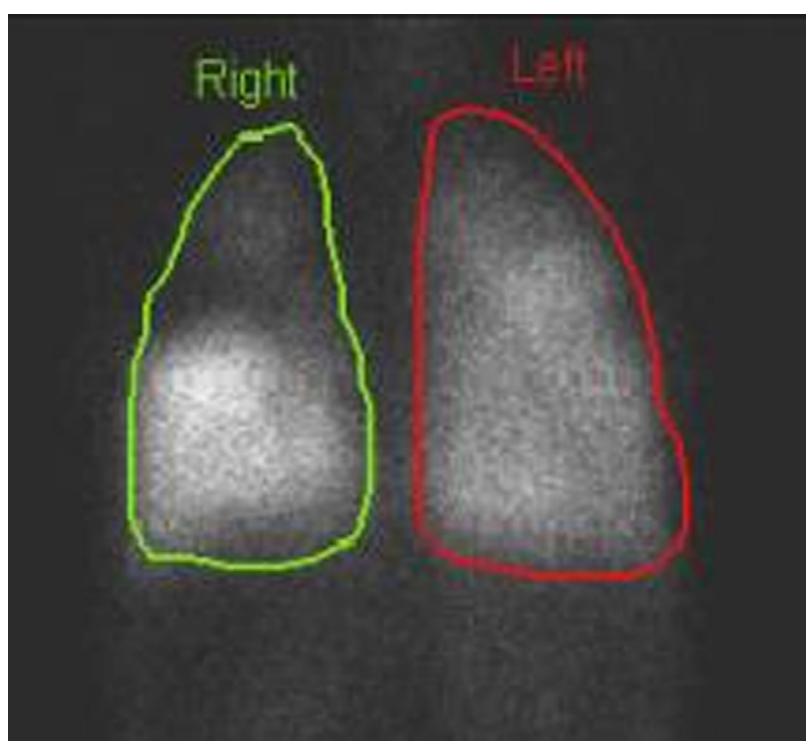

FIGURE 2. Lung perfusion scan showing even pulmonary blood flow distribution (left, $55 \%$; right, $45 \%$ ) and paucity of flow to the right upper lobe.

Although long-term outcomes with this approach are awaited, we speculate that a combination of unifocalization to the healthier pulmonary artery segments accessed via thoracotomy combined with the advantages of $\mathrm{cFVH}$ can potentially provide better outcomes for this group of complex patients.

\section{References}

1. Reddy VM, Petrossian E, McElhinney DB, Moore P, Teitel DF, Hanley FL. Onestage complete unifocalization in infants: when should the ventricular septal defect be closed? J Thorac Cardiovasc Surg. 1997;113:858-68.

2. Sawatari K, Imai Y, Kurosawa H, Isomatsu Y, Momma K. Staged operation for pulmonary atresia and ventricular septal defect with major aortopulmonary collateral arteries. New technique for complete unifocalization. J Thorac Cardiovasc Surg. 1989;98:738-50.

3. d'Udekem Y, Alphonso N, Norgaard MA, Cochrane AD, Grigg LE, Wilkinson JL, et al. Pulmonary atresia with ventricular septal defects and major aortopulmonary collateral arteries: unifocalization brings no long-term benefits. J Thorac Cardiovasc Surg. 2005;130:1496-502.

4. Sinha P, Moulick A, Jonas RA. Femoral vein homograft for neoaortic reconstruction in Norwood stage 1 operation. Ann Thorac Surg. 2009;87:1309-10.

5. Sinha P, Talwar S, Moulick A, Jonas R. Right ventricular outflow tract reconstruction using a valved femoral vein homograft. J Thorac Cardiovasc Surg. 2010;139:226-8

6. Seery TJ, Sinha P, Zurakowski D, Jonas RA. Femoral vein homograft for neoaortic reconstruction in the Norwood stage 1 operation: a follow-up study. J Thorac Cardiovasc Surg. 2013;146:550-6. 